\title{
Máscara espectrográfica para registro digital de espectros de fontes brilhantes $^{+*}$
}

Ademir L. Xavier Jr ${ }^{1}$

Agência Espacial Brasileira

Brasília - DF

\section{Resumo}

Neste trabalho, apresentamos diagramas esquemáticos para a construção de uma máscara espectrográfica adaptável à objetiva de uma câmera, a fim de se capturar espectros usando redes feitas de CD ou DVD. A máscara é feita de duas partes: um anel adaptador e um bloqueio em cotovelo para o registro correto de espectro no laboratório ou ao ar livre. Usando software livre, analisamos e discutimos a calibração em comprimento de onda para o espectro solar, o que permitiu a nós identificar muitos elementos químicos nele. Na conclusão, discutimos ainda alguns projetos interessantes a serem feitos por estudantes usando a ideia.

Palavras-chave: Espectroscópio; Espectro; Óptica; Processamento de Imagens; Redes de Difração.

\begin{abstract}
In this work we present schematic diagrams for the construction of a spectrographic mask attachable to a camera objective in order to capture spectra using simple CD or DVD gratings. The mask is made of two parts: an adapter ring and elbow-shaped blockage for suitable registration of spectra in the lab and outdoors. By using a free software, we analyze and discuss the calibration of the wavelength scale of the solar spectrum, which allows us to identify many chemical elements in it. In the conclusion, we further discuss some interesting projects to be carried out by students using the idea.
\end{abstract}

\footnotetext{
${ }^{+}$Spectrograph mask for digital registration of bright source spectra

* Recebido: setembro de 2016. Aceito: março de 2017.

${ }^{1}$ E-mail: ademir.junior@aeb.gov.br
} 
Keywords: Spectroscope; Spectrum; Optics; Image Processing; Diffraction Gratings.

\section{Introdução}

A descoberta e explicação dos espectros de luz tiveram impacto em três grandes áreas do conhecimento: astronomia, física e química. Na astronomia, espectros tiveram imediata aplicação na determinação da composição química dos astros. A química encontrou um processo poderoso de mensuração. Na física, a espectroscopia participou da revolução quântica, já que as linhas espectrais são as assinaturas que permitiram acessar os estados eletrônicos nos átomos. No começo, o uso de prismas fornecia as primeiras versões de espectros, sendo a luz do sol a mais usada para se demonstrar o processo de separação da luz em cores (NEWTON et al., 1996). Newton usou o arranjo de dois prismas para explicar porque seria preciso atribuir à luz e não ao prisma a propriedade das cores (SILVA et al., 2003). A partir da descoberta das linhas escuras no espectro do sol, o que foi feito por Joseph Fraunhofer (MONTEIRO et al., 2007), o processo moderno de produção das primeiras redes de difração (JACKSON, 2000) foi desenvolvido. Até hoje, as visualizações em laboratório de espectros impressionam bastante, já que, da compreensão mais profunda de sua causa, o aluno tem uma demonstração sensorial da manifestação da natureza íntima da matéria e seus estados quânticos.

Ao contrário de prismas, redes de difração fornecem um espectro linear (ou seja, a distribuição dos comprimentos de onda é linear com o ângulo de desvio da respectiva cor), que é consideravelmente mais débil do que o de prismas, já que ele não se origina da simples refração da luz (PALMER et al., 2005). Também, a fabricação de redes envolveu originariamente mecanismos delicados, que apenas modernamente foram suplantados por técnicas fotográficas (PALMER et al., 2005). De qualquer forma, redes de difração são dispositivos caros que exigem cuidados no manuseio. A alternativa do uso de prismas, além da não linearidade no ângulo de desvio da luz, também tem desvantagens relacionadas ao custo de cada unidade, que cresce proporcionalmente ao índice de refração usado. Recentemente, uma alternativa de baixíssimo custo foi adaptada (WAKABAYASHI et al., 2006; WAKABAYASHI, 2008), que faz uso de padrões de difração fornecidos por CDs (compact disks), largamente usados pela indústria fonográfica e de mídia digital. Discussões sobre esse dispositivo simples também podem ser encontradas em WIDIATMOKO et al. (2011), MONTOYA et al. (2012) e BYRNE (2003). Recentemente, a facilidade de obtenção de espectros por meio de redes baseadas em CDs (ou DVDs) tornou-se tão grande que um projeto de pesquisa público, o PublicLab (https://publiclab.org/wiki/spectrometer ${ }^{2}$ ), foi criado. Esse projeto faz uso de um espectrógrafo de rede em CD e tem como objetivo fornecer análises de espectro por fluorescência (WAHAB, 2007) para amostras biológicas de uso em ciências ambientais, uma vez que câmeras de dispositivos móveis (celulares) são bastante difundidas, o que permite o registro e envio de dados a distância.

\footnotetext{
2 Acesso em: jul. 2017.
} 
No Brasil, esses arranjos foram citados em dois trabalhos recentes (FRAZZOLI, 2012; OLIVEIRA, 2015). Neste trabalho, apresentamos diagramas de montagem tanto para uma versão de espectroscópio (para observação visual) como registro fotográfico, ou espectrógrafo. Esses arranjos podem ser feitos com materiais muito simples e permitem o registro de espectro tanto em laboratório como ao ar livre. Também explicamos como os espectros registrados podem ser analisados (calibração de comprimento de onda) usando recursos de software livre, fornecendo assim um método para a criação de uma "biblioteca" de espectros pelos alunos ${ }^{3}$, o que nos leva a uma incursão introdutória a um processo de tratamento de imagens.

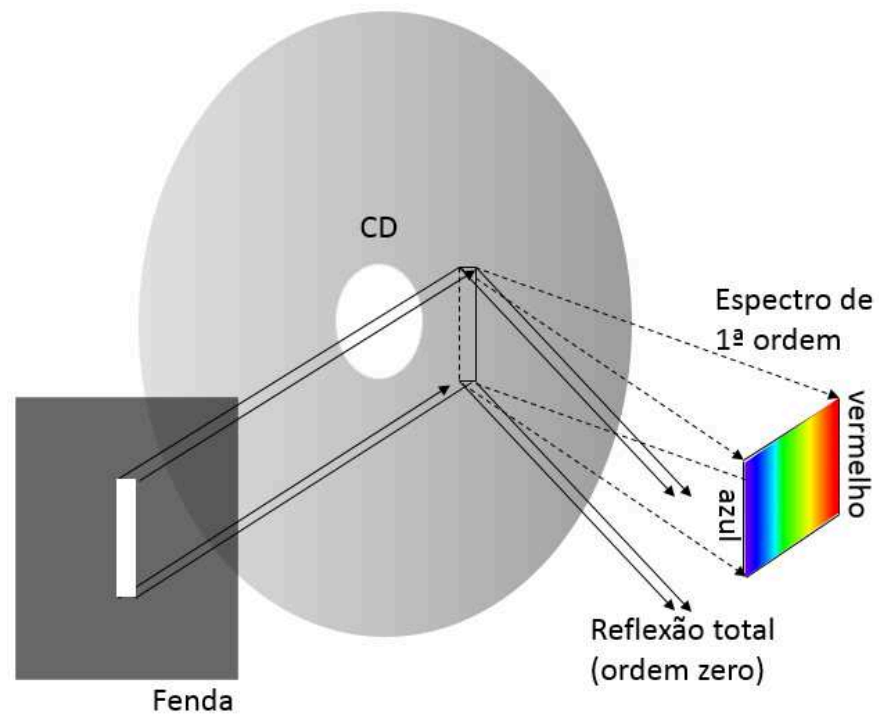

Fig. 1 - Diagrama esquemático do processo de reflexão e refração do feixe de luz de uma fenda na superfície do CD. O espectro em $1^{a}$ ordem é produzido, sendo que as cores de comprimento de onda maior são mais difratadas.

\section{Montagem de um espectroscópio de CD (DVD)}

O fenômeno de difração é bem descrito em muitos livros texto em física (BRAUN et al., 1994; NUSSENZVEIG, 1998). Ele também ocorre na superfície dos CDs modernamente usados em várias aplicações de mídia digital. A Fig. 1 traz um diagrama esquemático do arranjo geométrico da difração produzida com reflexão na superfície do $\mathrm{CD}$. A superfície do $\mathrm{CD}$ é caracterizada por inúmeros sulcos com certa densidade por milímetro (o que depende do tipo de CD; em DVDs, essa densidade chega a ser superior a 1000 linhas por mm). Esses sulcos produzem o fenômeno da difração, sendo que, quanto maior o comprimento de onda, tanto mais difratada será a radiação que nele incide (ou seja, tanto maior será o ângulo de difração). Acontece que a capa brilhante do CD pode ser removida. Para isso, usa-se uma fita fortemente adesiva na superfície da capa brilhante. A Fig. 2 (Direita) traz o aspecto final do pedaço de CD

\footnotetext{
${ }^{3}$ Veja, por exemplo <https://spectralworkbench.org/>. Acesso em: jul. 2017.
} 
com sua superfície brilhante removida. Antes disso, um pedaço (Fig. 2 (Esquerda)) do CD deve ser recortado. O plástico resultante é uma verdadeira réplica de rede, que permite a operação em "modo de transmissão".

Admitindo que a incidência seja normal na superfície da rede, o ângulo de refração para a $m$-ésima ordem é dado pela relação:

$$
\delta \sin \theta=m \lambda,
$$

sendo $\delta$ a separação entre os sulcos, $\lambda$ o comprimento de onda e $\theta$ o ângulo de difração. A luz amarela tem comprimento de onda $\lambda \sim 580 \mathrm{~nm}$. Para um DVD, o ângulo de difração é de aproximadamente $50^{\circ}$ para $\mathrm{m}=1$. Com isso, chegamos a $\delta \sim 1521$ linhas $/ \mathrm{mm}$ ou um espaçamento entre sulcos da ordem de $750 \mathrm{~nm}$, o que é uma distância comensurável com comprimentos de onda da luz.
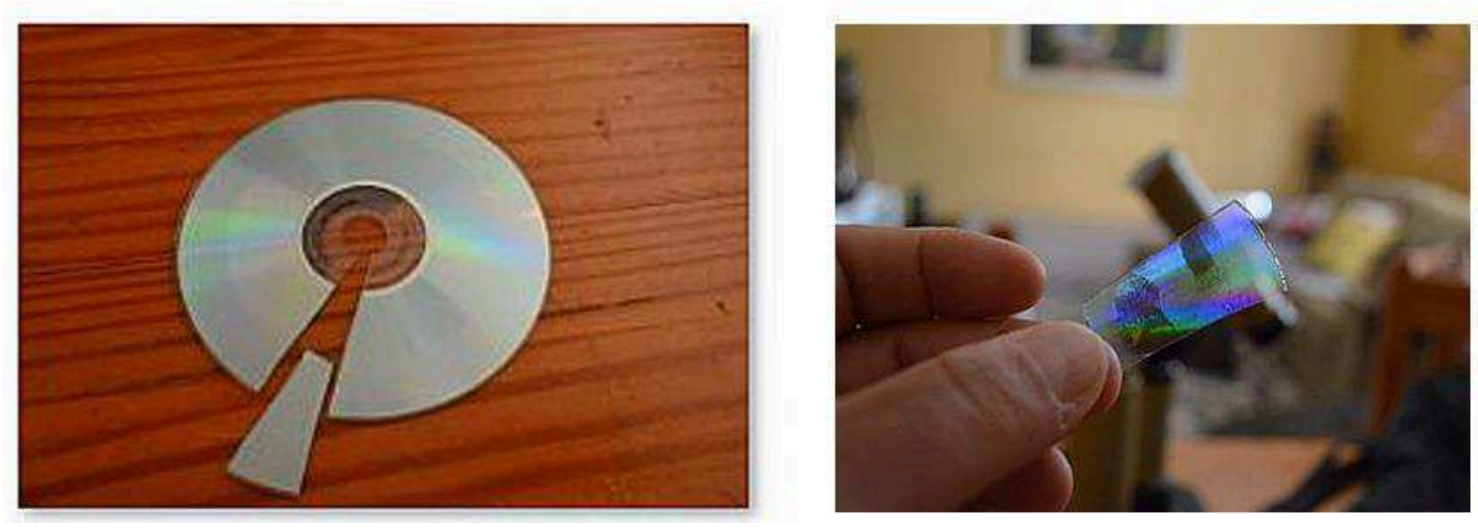

Fig. 2 - (Esquerda) Remoção de um pedaço de um CD para composição de uma rede improvisada. (Direita) Aspecto final da rede a partir da remoção da camada protetora brilhante.

Para a construção de um espectroscópio, é importante considerar que o feixe de luz, conforme a Fig. 1, deve incidir na rede improvisada de forma paralela aos sulcos. A distância entre a fenda e a superfície da rede também é importante. Em geral, quanto mais próximo a fenda estiver da rede, tanto mais brilhante será o espectro, mas menor será sua "resolução" (as linhas produzidas serão mais grossas, as bandas de cores mais estreitas). O oposto acontece com distâncias maiores, porém, o espectro resultante é consideravelmente menos brilhante. Um compromisso deve assim ser encontrado, e aqui sugerimos o uso da distância de $160 \mathrm{~mm}$ por facilitar a acomodação visual de objetos próximos ao olho.

\section{Montagem de uma máscara espectrográfica}

A máscara é um suporte feito em cartolina em que a "rede improvisada" é colocada na frente da objetiva de uma câmera (de preferência do tipo DSLR - "Digital Single-Lens Reflex 
Cameras", a razão será explicada mais adiante) e que permite a tomada de espectros de fontes brilhantes em "foco infinito". Esse arranjo permite obter de forma estável espectros de fontes mais débeis, daí a importância de a câmera ter regulagem de tempo de exposição. Essa máscara difere do arranjo da Seção II porque não há fenda e os espectros são formados a partir da difração da imagem do objeto distante na superfície do CD em modo "transmissão".

Para a construção da máscara é necessário:

- $\quad 1 \mathrm{CD}-\mathrm{R}$, de onde se extrai um fragmento conforme indicado anteriormente. Será necessário também retirar a proteção brilhante;

- Tesoura;

- $\quad$ Fita adesiva;

- Cartolina escura;

- $\quad$ Estilete;

- Câmera fotográfica (do tipo DSLR ou que permita ajuste de tempo de exposição).

A máscara é formada por duas peças. Um "anel de fixação", que permite a rede ser fixada na frente da objetiva da câmera e um "bloqueio em cotovelo", para permitir que apenas a luz proveniente de fonte distante seja difratada e entre na objetiva da câmera ao longo de seu eixo óptico. Isso está explicado na Fig. 3, onde se apresenta um desenho da objetiva com o anel de fixação, posicionamento da rede e ângulo de incidência típico (para o amarelo) conforme calculado anteriormente. $\mathrm{O}$ perfil de bloqueio foi desenhado de tal forma que apenas luz proveniente da $1^{\mathrm{a}}$ ordem do espectro atinja o sensor da câmera. Para isso, admite-se uma base (paralela à rede) de $60 \mathrm{~cm}$ de largura, onde são erguidas paralelas a $40^{\circ}$ em relação ao ângulo de incidência. Como o espectro é espalhado, não cometemos erro ao se admitir que o ângulo entre o plano da rede e o de incidência é da ordem de $50^{\circ}$, uma vez que quanto menor esse ângulo maior será o desalinhamento entre o eixo óptico da câmera e o feixe incidente. Em essência: dado o espalhamento do espectro, o ângulo de cotovelo pode estar entre $40^{\circ}$ a $50^{\circ}$.

A Fig. 4(a) traz o diagrama para montagem do anel de fixação. Esse desenho deve ser reproduzido em uma cartolina grossa, de preferência de cor preta em dupla face, recortado e colado. O diâmetro interno, de $71 \mathrm{~mm}$, é o da objetiva da câmera da marca Nikon que foi a utilizada para a obtenção das imagens. Esse diâmetro deve ser modificado para acomodar outros tipos de objetivas. Note que o anel menor tem $24 \mathrm{~mm}$ de diâmetro, mas pode ser maior. Esse é o tamanho também usado para a "replica" ou pedaço de CD que serve com rede de difração e que deve ser colado na parte interna, voltada para a objetiva da câmera. $O$ desenho para a montagem do bloqueio pode ser visto na Fig. 4(b). Esse elemento pode ser construído igualmente em cartolina e, idealmente, seu interior deve ser negro para aumentar o contraste dos espectros registrados. Observe que os polígonos A e A' na Fig. 4(b) são imagens especulares um do outro, de forma que as medidas fornecidas para A são as mesmas de A', observadas as correspondências entre cada face. As abas de colagem têm aproximadamente $1 \mathrm{~cm}$ de largura. 


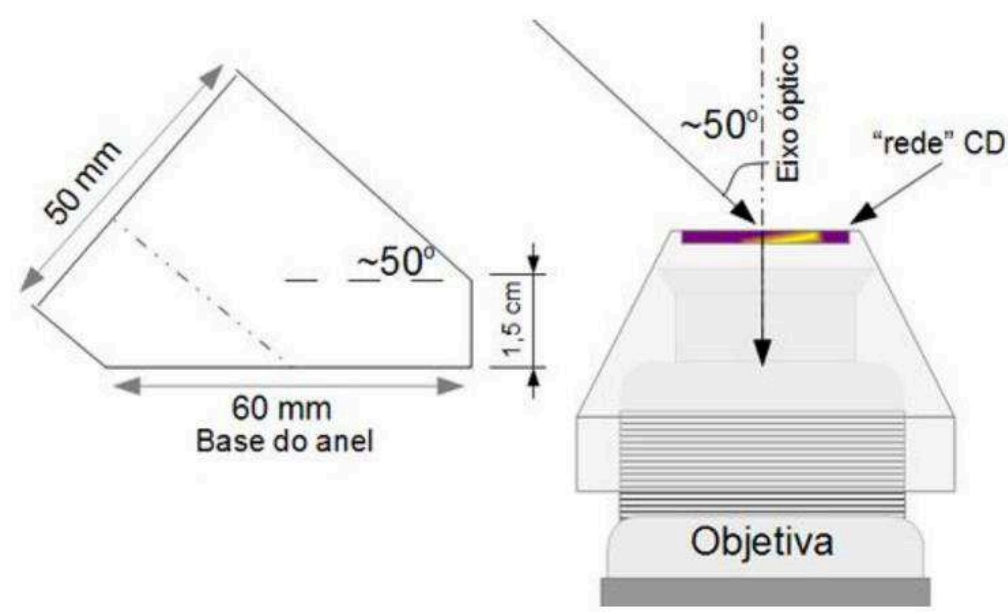

Fig. 3 - (Esquerda) Diagrama esquemático do bloqueio em cotovelo para a máscara (esquerda) onde foi usado $50^{\circ}$ como ângulo entre o plano da rede e os raios incidentes ( diferença de $10^{\circ}$ é desprezível). À direita pode-se ver o ângulo de incidência dos raios de entrada (amarelo), a fim de que o espectro em primeira ordem seja paralelo ao eixo óptico da câmera.

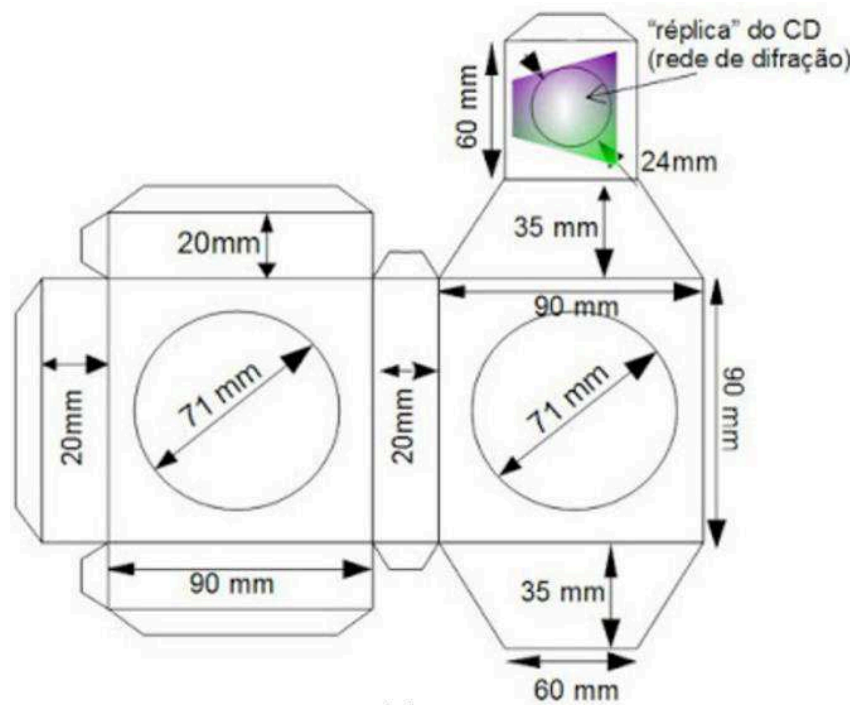

(a)

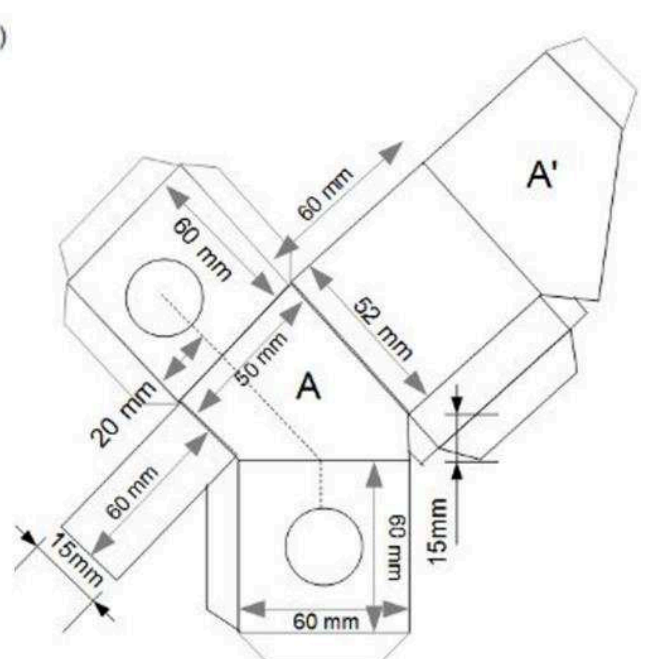

(b)

Fig. 4 (a)-Diagrama para a montagem do anel de fixação. Note a posição da máscara. Os círculos devem ser vazados e adaptados conforme o diâmetro da câmera utilizada. As abas de fixação lateral tem $1 \mathrm{~cm}$ de largura. (b) Diagrama esquemático para montagem do bloqueio em cotovelo. 
Uma vez acomodada a câmera em um tripé e montado o anel na objetiva, registros de espectros podem ser feitos. Recomendamos o uso de um tripé por razões óbvias e típicas da fase de teste. $\mathrm{O}$ aspecto final do anel pode ser visto à esquerda na Fig. 5. Como essa imagem mostra, a rede ficará paralela à objetiva da câmera (conforme o diagrama à direita da Fig. 3). Se apenas esse anel for utilizado, a câmera pode registrar espectros e, ao mesmo tempo, uma imagem. Isso está mostrado na Fig. 5 (Direita) para uma lâmpada de iluminação interna. O espectro pode ser visto juntamente com a imagem de fundo. Como o padrão de difração é de uma fonte no foco do plano da imagem, tanto o plano como o espectro aparecem simultaneamente na imagem.
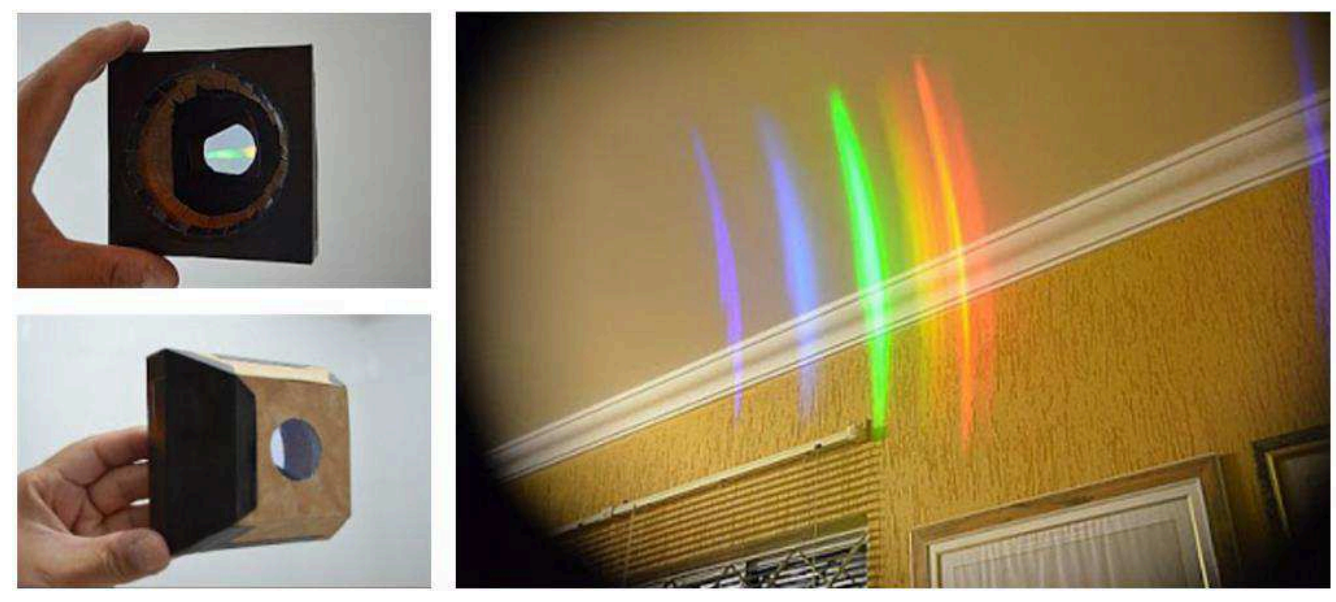

Fig. 5 - (Esquerda) Aspecto final do anel de fixação com a rede colocada na posição. (Direita) Imagem capturada com o anel fixado à câmera de uma lâmpada fluorescente moderna.

\section{Exemplos de espectros obtidos}

A Fig. 6 traz uma imagem do espectro do sol não processado, tal como registrado através da máscara formada pelo anel e pelo bloqueio. Para obter esse espectro, o reflexo do sol em um anteparo distante (vidro de um automóvel) foi utilizado. Uma vez que a rede do CD espalha muito a luz, tempos de exposição da ordem de mais de $1 \mathrm{~s}$ devem ser usados em registros noturnos e apenas objetos brilhantes podem ser resolvidos. Diversas fontes noturnas podem ser vistas na Fig. 7 e Fig. 8. O espectro da lua é visto no primeiro caso, quando foi necessário $10 \mathrm{~s}$ de tempo de exposição em ISO 320. Como esperado, esse espectro não difere do espectro solar. A Fig. 8 traz dois espectros de lâmpadas de iluminação pública distantes, sendo que também $10 \mathrm{~s}$ foram usados em ISO 2500. No caso do espectro lunar, as linhas de Fraunhofer também podem ser vistas, ainda que nenhum tipo de fenda tenha sido utilizado. Para tanto, a menor relação f/D foi usada, de forma que o diâmetro do disco da lua foi o menor possível, para resolver ao máximo as linhas. 


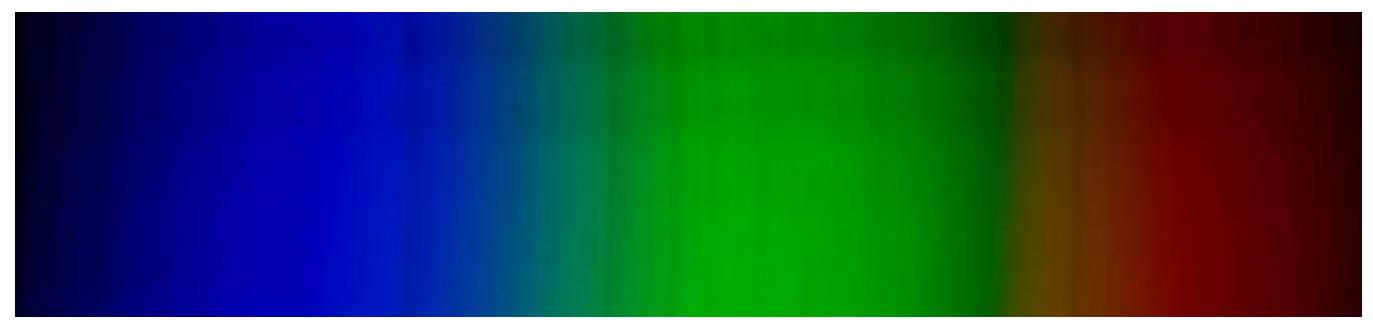

Fig. 6 - Espectro do Sol não processado obtido com a máscara. Nele é possível ver as famosas "linhas de Fraunhofer". (Nikon D5100 F5.6, 1/3 s, ISO 100).

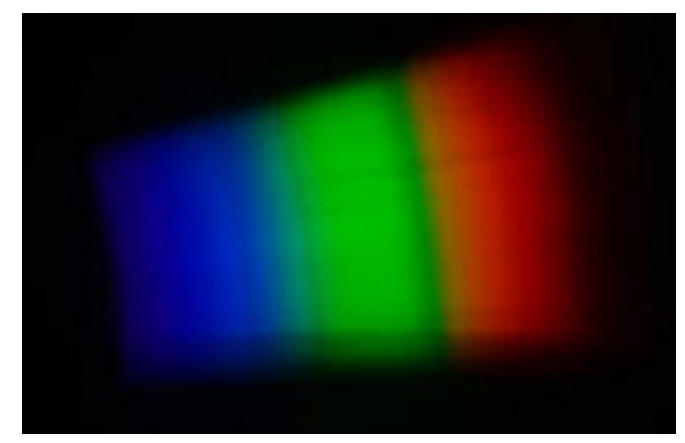

Fig. 7 - Espectro da lua obtido com a máscara mostrando as linhas de Fraunhofer. (Nikon 5100, F4.5, 10s, ISO 320).

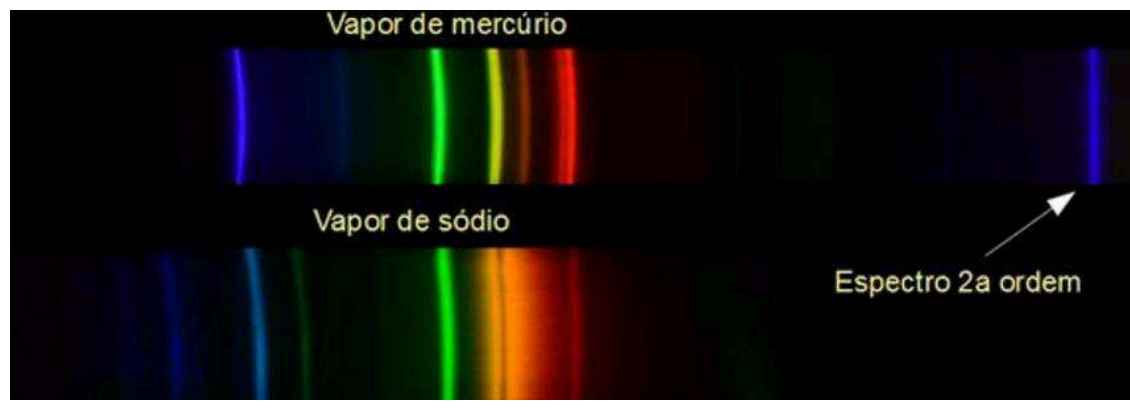

Fig. 8 - Espectros de lâmpadas de iluminação pública obtidos com a máscara. Uma linha do espectro de segunda ordem aparece também registrado na imagem superior (lâmpada de vapor de mercúrio). Nikon 5100, F4.5, 10s, ISO 2500.

\section{Extraindo informação quantitativa do espectro solar}

Uma vez fotografado um espectro, é possível obter informação quantitativa a partir dele. Para isso, é necessário extrair a matriz da imagem, o que pode ser feito por meio de software livre. Escolhemos o ImageJ (FERREIRA et al., 2012), que possui diversas ferramentas para a extração de medidas de imagem. Depois de se instalar o programa ImageJ, a janela principal deve ser aberta. Clique em "File" para abrir uma imagem. Escolhemos analisar a imagem da Fig. 6, que apresenta o espectro solar como registrado por intermédio da máscara espectrográfica. 


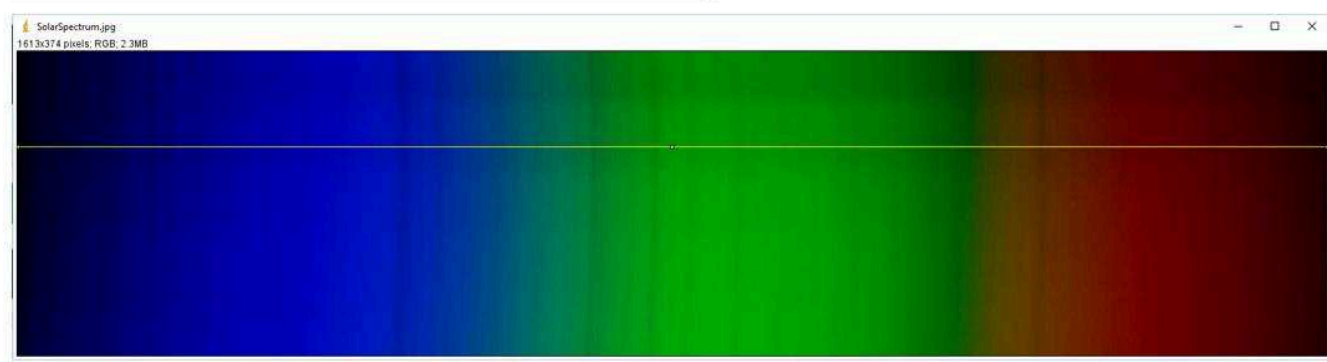

Fig. 9 - Janela do software ImageJ e imagem do espectro solar aberta com ele. A ferramenta "Straight" permite extrair os dados de uma linha da matriz de imagem conforme mostrado pela reta amarela.

Nosso objetivo é identificar as linhas escuras vistas na imagem e associá-las a um comprimento de onda, ou seja, realizar um procedimento de "calibração" da escala de frequências da luz. Para isso, não precisamos nos importar com os três canais de cores usados pelo sensor (uma câmera digital) para capturar a imagem e nem com o valor relativo das intensidades. Extraímos, com base na ferramenta "Straight" disponível no ImageJ (é a quinta caixa como vista na parte de cima da Fig. 9) uma "amostra" dos dados conforme indicada pela linha amarela da parte inferior da Fig. 9. Uma vez selecionada essa linha, pode-se ter um gráfico das intensidades, clicando-se na barra de ferramentas, "Analyze $\Rightarrow$ Plot Profile”, que gera um gráfico como da Fig. 10.

Essa figura mostra a distribuição de intensidades da linha amarela selecionada em uma escala arbitrária, que corresponde à posição das colunas de pixels na imagem. É possível extrair informações de mais de uma linha ao mesmo tempo, clicando-se sobre a ferramenta de reta ("Straight") e escolhendo, na janela de "Line Width", uma largura conveniente. Ao se selecionar um novo perfil ("Plot Profile"), um gráfico semelhante ao da Fig. 10 será gerado, com um perfil ponderado de intensidades. Podemos fazer isso escolhendo Line Width da ordem de 30.

Feito isso, as medidas podem ser extraídas clicando-se no botão "Save" que aparece na parte inferior do gráfico do perfil (como visto na Fig. 10). Por "default", esse procedimento gerará um arquivo denominado "Value.xls" que pode ser lido por um programa de planilha eletrônica, como é o caso do software livre "Apache Open Office” (AGOSTINHO et al., 2006) ou do Microsoft Excel. É possível ver que o arquivo aberto é formado por duas colunas. $\mathrm{Na}$ primeira, a identificação do pixel (coluna) da imagem; na segunda, um valor que corresponde à intensidade média do intervalo de linhas capturado. A escala da primeira coluna é relativa e deverá ser substituída por outra correspondendo ao comprimento de onda. Ao se disponibilizar os dados em arquivo, é possível exibir o mesmo gráfico (como o da Fig. 10), desta vez dentro do ambiente da planilha. 


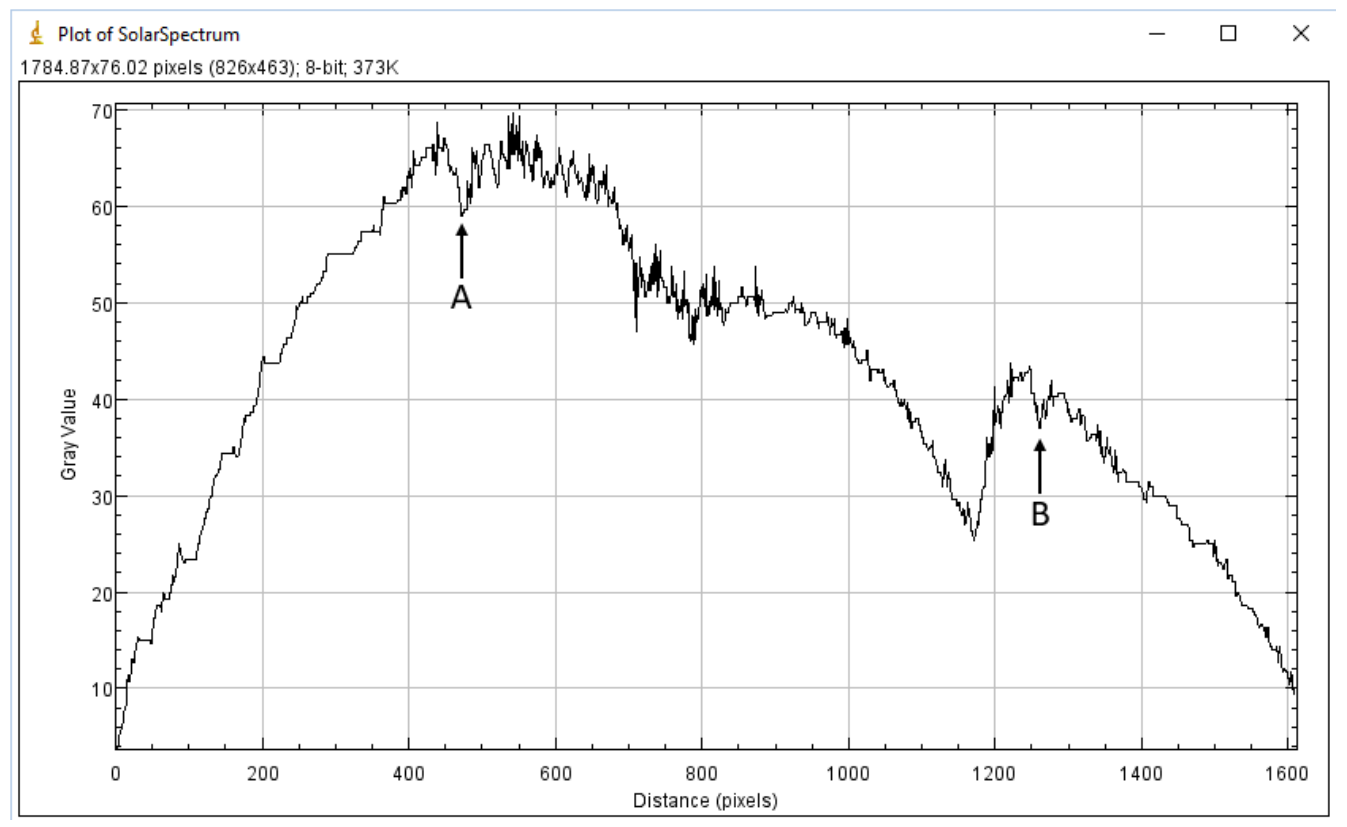

Fig. 10 - Perfil de intensidades ao longo da linha amarela da Fig. 9 (o eixo das abcissas corresponde à indexação das colunas na matriz da imagem e a ordenada corresponde a uma intensidade na escala de 8 bits.

O processo de calibração consiste em identificar no mínimo duas linhas de absorção (preferencialmente separadas por vários comprimentos de onda) e determinar o número na primeira coluna que corresponde a esse comprimento. De forma analítica, seja $\lambda_{1}$ o comprimento de onda da primeira linha, $\lambda_{2}$ o da segunda linha, $L_{1}$ o índice (pixel) da primeira coluna no arquivo corresponde a primeira linha e $\mathrm{L}_{2}$ o correspondente a segunda linha, então qualquer comprimento de onda na posição de pixel L pode ser lido no gráfico ao se usar a função:

$$
\lambda(L)=\lambda_{2}+\left(L-L_{2}\right) \frac{\lambda_{1}-\lambda_{2}}{L_{1}-L_{2}} .
$$

Essa função pode ser usada porque a distribuição de comprimentos de onda é linear (e aqui aproveitamos a vantagem do uso de redes de difração ao invés de prismas) com o ângulo de difração e, portanto, com a posição do pixel (exceto por efeitos de curvatura de campo, que são aqui desprezados). Deve-se, portanto, identificar as duas linhas e criar uma tabela de calibração.

Uma identificação pode ser vista na Fig. 10 pelas setas nas letras A e B. Esses dois mínimos correspondem, respectivamente, as linhas F e D na classificação de Fraunhofer, correspondentes aos comprimentos de onda de 486,1 nm para o $\mathrm{H} \beta$ e 589,7 nm para o Sódio (ROWLAND, 1895; MOORE et al., 1966). Por meio de um software de edição de planilhas, é possível, nos dados que coletamos, determinar que essas duas linhas estão representadas pelos mínimos na posição de pixel 475 e 1261 na imagem, respectivamente. Portanto, a função de calibração será $\lambda(L) \cong[589,7+0,13(L-1261)] \mathrm{nm}$. Observe que, com essa lei, a resolução 
do espectrógrafo é algo próximo a 1,3Å, o que não é suficiente para resolver o dubleto do Sódio (589,0 nm e 589,6 nm) e indica a limitação no par CD-câmera usada.

A função de calibração pode ser facilmente implementada na planilha e o resultado do espectro em termos do comprimento de onda pode ser visto na Fig. 11.

Esse gráfico mostra um espectro onde a intensidade foi convertida em uma escala de 0 a 1 e como função do comprimento de onda em nanômetros.

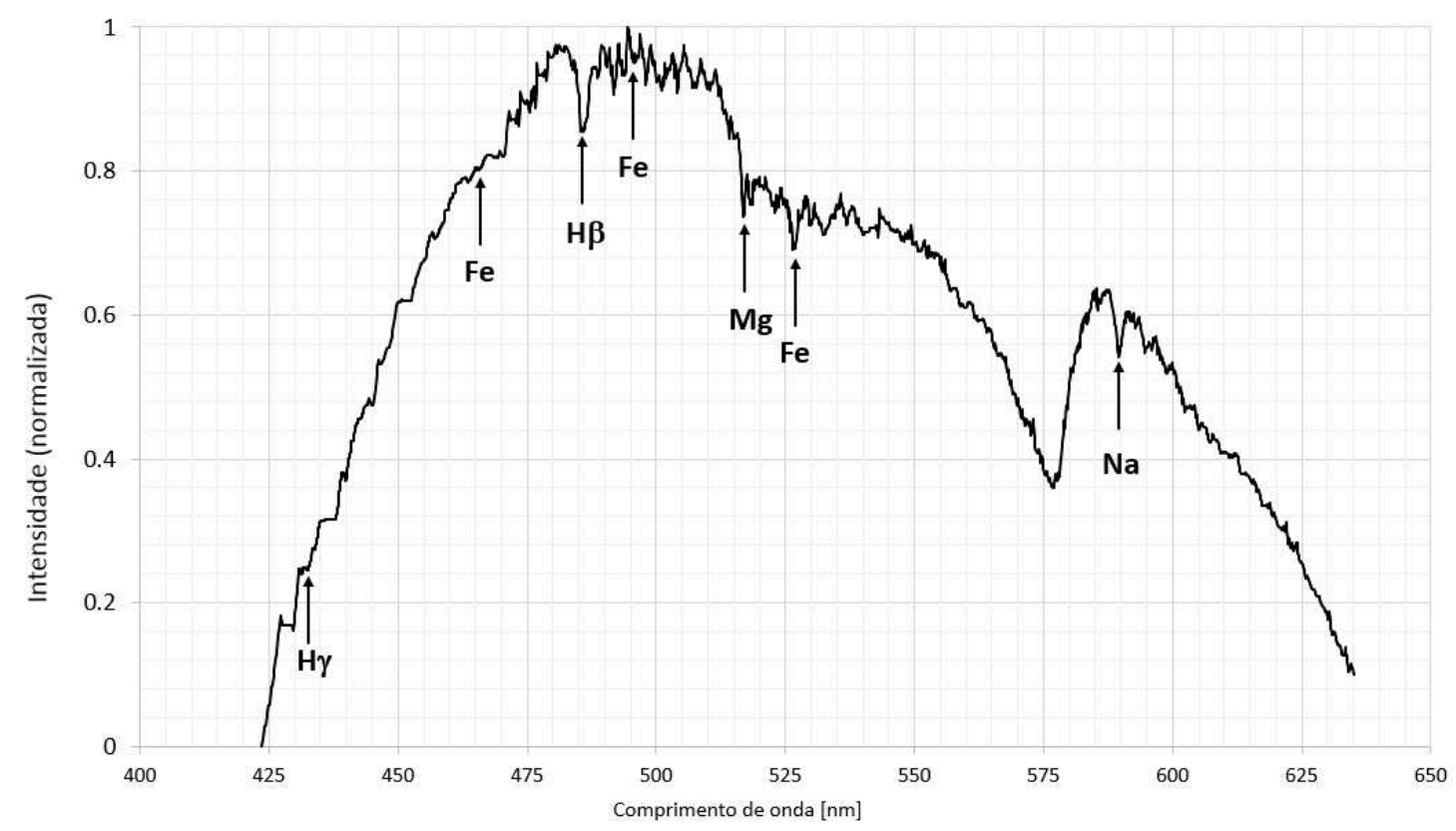

Fig. 11 - Espectro com intensidade normalizada e escala de comprimento de onda. Alguns elementos químicos são identificados a partir da calibração.

É importante considerar que, para cada aquisição que se fizer do espectro, uma nova calibração da escala de comprimento de ondas deverá ser feita caso a arranjo geométrico seja modificado (posição relativa da rede em relação à câmera). Na Fig. 11 são indicadas as linhas de outros elementos químicos (MOORE et al., 1966) encontrados na imagem, não obstante a forte absorção da luz causada pelos filtros RGB da câmera ao longo de toda faixa do visível.

Uma parte densamente populada de linhas na região do $\mathrm{H} \beta$ é vista com a identificação dos elementos químicos na Fig. 12 entre 482,5 nm e 512,5 nm tão só como resultado da calibração em comprimento de onda. Sobressai o grupo do Fe I (GOLDBERG et al., 1964) e outros metais como o Cromo e o Níquel. Esse gráfico mostra o grau de detalhes quantitativos que é possível obter com esse arranjo de espectrógrafo simples, usando uma máscara de difração feita de CD. 


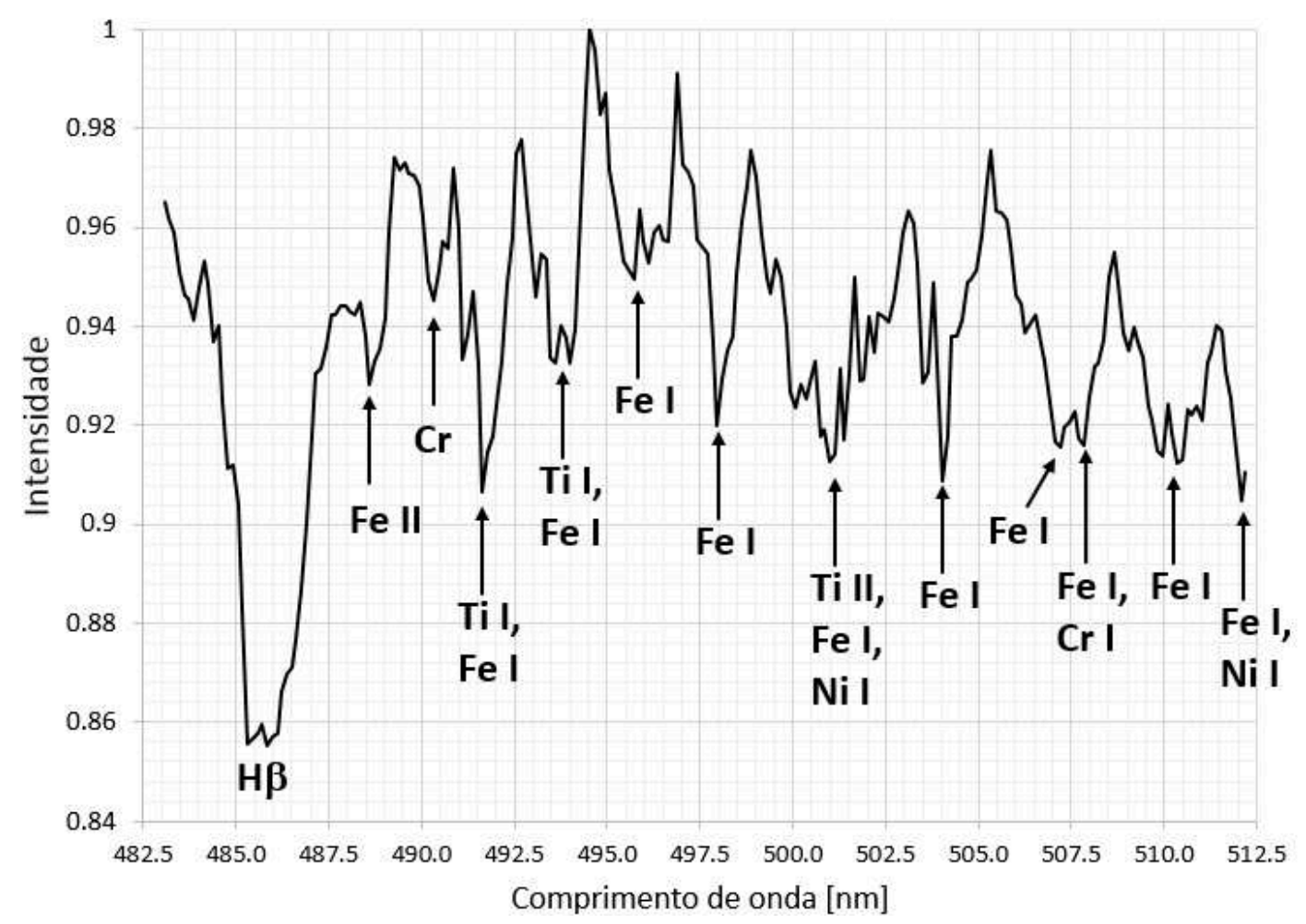

Fig. 12 - Zoom da Fig. 11 no intervalo entre 482,5 nm e 512,5 nm identificando elementos químicos (principalmente o grupo do Fe I) no espectro solar. Para a identificação usouse a tabela fornecida em (MOORE et al. 1966).

\section{Conclusões}

Seria possível substituir completamente as redes de difração comerciais por réplicas improvisadas em CD? A resposta é obviamente não porque as superfícies em plástico dos CDs não são opticamente preparadas. Isso significa que existem irregularidades maiores que o comprimento de onda na superfície delas e que, portanto, não é viável a substituição completa, sendo que essa desvantagem limita severamente a resolução final desse tipo de rede. Além disso, os sulcos não são paralelos, mas concêntricos, o que contribui para um espalhamento muito maior da luz. Numa rede de difração comercial por reflexão, por exemplo, os sulcos são produzidos de forma a haver um máximo de intensidade da luz em $1^{\mathrm{a}}$ ordem (em detrimento de outras ordens), resultando em espectros de intensidade otimizada (PALMER et al., 2005; JAMES, 2007). A resolução final dos espectros obtidos é pequena (provavelmente superior a >10 $\mathrm{nm}$ ), por causa da simplicidade do arranjo óptico - não há nenhum elemento de "ampliação". Ainda que seja possível ampliar a saída do feixe difratado, a falta de homogeneidade da película de plástico do CD limita a resolução final. Entretanto, não deixa de ser surpreendente a qualidade dos espectros obtidos com o arranjo simples, ou seja, a relação "custo/benefício" é bastante compensadora, como pode ser visto pela identificação dos elementos químicos no espectro solar na Fig. 12. 
Em particular, é possível usar o arranjo da máscara para o registro de espectros em laboratório ou ao ar livre. No último caso, objetos brilhantes podem ser registrados. Por exemplo, provavelmente é possível obter um bom registro do espectro do planeta Vênus em sua fase de máximo brilho com esse arranjo simples. Talvez até mesmo o espectro de Sirius ( $\alpha$ Canis Majoris) possa ser registrado com algum esforço. No primeiro caso (laboratório), são possíveis demonstrações envolvendo a exibição de diversas linhas de emissão ou estudo da luz de descarga de gases. O uso de uma chama, por exemplo, permite a observação e o registro do espectro de sais e outras substâncias. Um projeto interessante que pode ser feito por alunos é o registro fotográfico do engrossamento das linhas do oxigênio no espectro solar por extinção da luz (WHITE, 1990; SCHAEFER, 1986), quando o sol está próximo do horizonte. Nesse caso, o perfil das linhas do oxigênio na região do vermelho (usando sempre a mesma configuração de parâmetros de imagem, exposição, ISO) deve ser periodicamente registrado junto com a elevação do sol em relação ao horizonte.

O processo de calibração no "eixo x" demonstrado neste trabalho é facilitado pelo caráter linear do desvio da luz provocado pela rede de difração. Essa calibração é feita por meio de uma regra simples que usa a identificação de pelo menos duas linhas no espectro e utiliza apenas softwares de tratamento de imagem livres como é o caso do ImageJ. Se o arranjo do espectrógrafo permanecer fixo, a mesma calibração poderá ser aplicada ao espectro obtido de fontes diversas, porém, se houver qualquer mudança de posicionamento, uma nova calibração deverá ser obtida. Já a calibração no "eixo y" é mais complexa e envolve uma tomada preliminar de um espectro de uma fonte de luz calibrada - isto é, uma fonte cuja intensidade espectral seja conhecida. Com base na curva de resposta de intensidade obtida pelo espectrógrafo (que depende da difração no CD e dos filtros da câmera usada para o registro), seria possível obter a resposta espectral do sensor, ligada a sua sensibilidade. Com essa resposta, o perfil calibrado em " $y$ " do espectro para qualquer outra fonte poderia ser obtido.

\section{Referências bibliográficas}

AGOSTINHO, N. U.; DAL-RIOS NEVES, L.; BARBOSA, A. M.; NEPOMUCENO, E. G. Softwares livres no ensino de engenharia: uma atitude socialmente justa, economicamente viável e tecnologicamente sustentável. In: CONGRESSO BRASILEIRO DE ENSINO DE ENGENHARIA, 2006. Disponível em:

<http://www.abenge.org.br/CobengeAnteriores/2006/artigos/4_170_438.pdf>. Acesso em: 31 mar. 2017.

BRAUN, L. F. M.; BRAUN, T. A montagem de Young no estudo da interferência, difração e coerência de fontes luminosas. Caderno Catarinense de Ensino de Física, Florianópolis, v. 11, n. 3, p. 184-195, 1994. Disponível em:

<https://periodicos.ufsc.br/index.php/fisica/article/view/7146> Acesso em: 31 mar. 2017. 
BYRnE, A. Compact disk spectroscopes revisited! The Physics Teacher, v. 41, n. 3, p. 144$145,2003$.

FERREIRA, T.; RASB, W. ImageJ user guide. 2012. Disponível em: <https://imagej.nih.gov/ij/docs/guide/>. Acesso em: 31 mar. 2017.

FRAZZOLI, J. C. F. Astrofísica de estrelas compactas como atividade suplementar para o ensino médio. 2012. Dissertação (Doutorado em Ensino de Física) - Universidade Federal do Rio de Janeiro, Rio de Janeiro.

GOLDBERG, L.; KOPP, R. A.; DUPREE, A. K. The Abundance of Iron in the Solar Photosphere. Astrophysical Journal, v. 140, p. 707, 1964.

JACKSON, M. W. Spectrum of belief: Joseph von Fraunhofer and the craft of precision optics. Cambridge, Massachusetts: Mit Press, 2000. 296 p.

JAMES, J. Spectrograph design fundamentals. Cambridge: Cambridge University Press, 2007. 204 p.

MONTEIRO, M. A.; NARDI, R. A utilização da História da Ciência no Ensino de Física: investigando o contexto da construção do espectroscópio de chamas. In: SIMPÓSIO NACIONAL DE ENSINO DE FÍSICA, XVII, 2007. Disponível em: <http://www.cienciamao.usp.br/tudo/exibir.php?midia=snef\&cod=_autilizacaodahistoriadac $>$. Acesso em: 31 mar. 2017.

MONTOYA, E.; BALTUANO, O.; ARBILDO, A. Espectrómetro de bajo costo y alta performance para radiación visible. Informe Científico Tecnológico, v. 12, p. 83-89, 2012. Disponível em: <http://dspace.ipen.gob.pe/handle/ipen/135>. Acesso em: 31 mar. 2017.

MOORE, C. E.; MINNAERT, M. G. J.; HOUTGAST, J.; ROWLAND, H. A. The solar spectrum $2935 \AA$ to $8770 \AA$ A. Second revision of Rowland's Preliminary table of solar spectrum wavelengths. Ed. National Bureau of Standards, US Government, 1966. 349 p. v. 61.

NEWTON, I.; ASSIS, A. K. T. Óptica. São Paulo: Edusp, 1996. 294 p.

NUSSENZVEIG, H. M. Física Básica. 1. ed. São Paulo: Ed. Blucher, 1998. 444 p. v. 4.

OLIVEIRA, H. J. S. Desenvolvimento de um espectrofotômetro para medidas de absorção/emissão na região do visível utilizando mini lâmpada incandescente, mídia de DVD e smartphone. 2015. Dissertação (Mestrado em Química) - Universidade Federal da Paraíba, João Pessoa. Disponível em: < http://tede.biblioteca.ufpb.br/handle/tede/8187>. Acesso em: 31 mar. 2017.

PALMER, C. A.; LOEWEN, E. G. Diffraction grating handbook. 6. ed. Springfield, USA: Newport Corporation, 2005. 271 p. 
ROWLAND, H. A. Preliminary Table of Solar Spectrum Wavelengths I. Astrophysical Journal, v. 1, p. 29, 1895. Disponível em: <http://adsabs.harvard.edu/full/1895ApJ.....1...29R> Acesso em: 31 mar. 2017.

SCHAEFER, B. E. Atmospheric extinction effects on stellar alignments. Journal for the History of Astronomy Supplement, v. 17, p. S32, 1986.

SILVA, C. C.; DE ANDRADE MARTINS, R. A teoria das cores de Newton: um exemplo do uso da história da ciência em sala de aula. Ciência \& Educação, v. 9, n. 1, p. 53-65, 2003. Disponível em: <http://www.scielo.br/pdf/ciedu/v9n1/05.pdf>. Acesso em: 31 mar. 2017.

WAKABAYASHI, F.; HAMADA, K. A DVD spectroscope: A simple, high-resolution classroom spectroscope. Journal of Chemical Education, v. 83, n. 1, p. 56, 2006.

WAKABAYASHI, F. Resolving spectral lines with a periscope-type DVD spectroscope. Journal of chemical education, v. 85, n. 6, p. 849, 2008.

WAHAB, F. Fluorescence spectroscopy in a shoebox. Journal of chemical education, v. 84, n. 8, p. 1308, 2007.

WIDIATMOKO, E.; SUTRISNO W.; BUDIMAN.; ABDULLAH M., KHAIRURRIJAL K. A simple spectrophotometer using common materials and a digital camera. Physics Education, v. 46, n. 3, p. 332, 2011.

WHITE, W. H. The components of atmospheric light extinction: A survey of ground-level budgets. Atmospheric Environment. Part A. General Topics, v. 24, n. 10, p. 2673-2679, 1990. 